\title{
Hypertrophy and Liver Function in ALPPS: Correlation with Morbidity and Mortality
}

\author{
Danby Kang ${ }^{a}$ Erik Schadde ${ }^{a-c}$ \\ a Department of Surgery, Rush University Medical Center, Chicago, IL, USA; \\ ${ }^{b}$ Cantonal Hospital Winterthur, Winterthur, Switzerland; \\ c Institute of Physiology, Center for Integrative Human Physiology, University of Zurich, Zurich, Switzerland
}

\section{Keywords}

ALPPS · Liver function · Posthepatectomy liver failure

\section{Summary}

Background: ALPPS (associating liver partition and portal vein ligation for staged hepatectomy) was introduced with the promise to reduce posthepatectomy liver failure (PHLF) in extended hepatectomies but has higher morbidity and mortality rates compared to conventional methods of volume enhancement. There are few studies of the incidence of PHLF after ALPPS and little information on how to avoid PHLF by functional testing. It remains unclear what causes the compromise in liver function despite rapid volume gain and if any of the modifications proposed reduce the incidence of PHLF. This review summarizes published data on this topic. Methods: This is a systematic review that studies literature on the incidence of liver failure and assessment of liver function following ALPPS as well as modifications of the existing technique. Articles were searched in PubMed, evaluated, selected, and tabulated. Results: The literature search revealed 326 articles that met the selection criteria. PHLF criteria as defined by the International Study Group of Liver Surgery (ISGLS) were the most commonly used criteria, but PHLF was frequently not defined. PHLF occurred most frequently after stage 2 of ALPPS at around $30 \%$ in most larger studies. Hepatobiliary scintigraphy showed a discrepancy between volume and functional growth of the liver. Function increase was only $50 \%$ compared to volume increase. Mechanistic explanations using histologic analyses have been given to explain the immaturity of the liver after rapid hypertrophy. Modifications of ALPPS showed a comparable volumetric gain when compared to classic ALPPS, but data were lacking to assess PHLF. Conclusion: ALPPS has relatively high rates of PHLF, morbidity, and mortality. This may be explained by data demonstrating functional growth when compared to volume growth. ALPPS should not be performed without functional assessment and with caution.

(C) 2017 S. Karger GmbH, Freiburg

\section{Introduction}

The amount of liver that can be removed by liver resection is limited by the metabolic and functional capacity of the future liver remnant (FLR) after resection. The prospective postoperative functional liver capacity has for the longest time been quantified by the volume of this FLR as determined by cross-sectional imaging. Therefore, surgeons have developed strategies to increase the volume of the remnant liver by either minimizing the amount of liver resected [1], downsizing the mass to be resected, or increasing the FLR prior to resection by occlusion of the contralateral portal vein [2]. Volume increase after portal vein occlusion is by no means as fast as volume increase after liver resection proper. Data from live donor hepatectomy and standard liver resections show that the liver volume almost doubles within 10 days after hemi-hepatectomy [3]. In contrast, both surgical portal vein ligation (PVL) and portal vein embolization (PVE) require 3-6 weeks of waiting time and a re-evaluation before the tumor-involved portion can be safely resected [4]. The congruity of volume and function was never really challenged, except by some who considered whether PVE may have a larger impact on liver function beyond its modest impact on liver volume over time [5]. These authors must have felt that PVE increased the function of the FLR even if the volume only changed a little bit.

\section{KARGER}

(๑) 2017 S. Karger GmbH, Freiburg
Erik Schadde, MD FACS FEBS (HPB) 
In 2012, Associating Liver Partition and Portal vein ligation for Staged hepatectomy (ALPPS) was introduced and reduced the 3-6 weeks waiting time while increasing the extent of FLR growth [6]. The procedure hailed a simultaneous deportalization and insitu parenchymal transection to induce the same rapid liver growth that can be observed after liver resection proper and allowed the resection of extensive tumor masses in 2 stages in 1-2 weeks. The inaugural ALPPS report describes a median volumetric increase of $74 \%$ over a median of 9 days [6], and the first multicenter report of an international registry reported $81 \%$ volume increase over a median of 7 days $[6,7]$.

Initially, ALPPS was praised as the most important surgical innovation in liver surgery for years [8], because presumably it eliminated the fear of posthepatectomy liver failure (PHLF), the most common and the most feared complication of extended resections. However, the first analyses showed that ALPPS has a perioperative mortality of $9 \%$ and a complication rate of Clavien-Dindo $>3 \mathrm{a}$ of $40 \%$ [9]. This appears high when compared to 2-stage hepatectomies with a mortality of $3 \%$ and a major morbidity rate of $40 \%$ in a recent meta-analysis [10]. Lack of experience and the difficulty of the procedure served as an explanation for these disappointing outcomes of ALPPS [11]. However, when complications and mortality were dissected in a more granular fashion, it became obvious that $75 \%$ of the reported 90 -day mortalities had to be attributed to PHLF and that liver failure criteria were present in $14 \%$ of patients even after stage 1 when no liver tissue had been resected yet [9]. Although it remained difficult to determine how much major morbidity is simply procedure-related and not actually caused by PHLF, this analysis raised the suspicion that ALPPS may in fact generate rapid volumetric growth without the congruent growth in liver function that is required for adequate postoperative recovery. It also appeared that there had been an over-reliance on liver volume when deciding whether patients can undergo stage- 2 resection, and that rapidly grown livers are not made of the 'same material' as liver grown slowly after PVE. This concern has led some surgeons to routinely evaluate the function of the growing FLR rather than relying on volume assessment alone.

The purpose of this review is to summarize what we know about liver-related mortality and morbidity after ALPPS and to enumerate the studies that have attempted to shed light on the conundrum of volume and function in ALPPS. The review also investigates which mechanistic explanations have been presented to understand the functional deficiency of the rapidly volume-expanded liver in ALPPS. Finally, we ask if any of the proposed 'better' modifications of the ALPPS operation do not have the problem of functional deficiency of 'classic' ALPPS.

\section{Methods}

PubMed was searched using the following algorithm: ((('ALPPS'(Title/Abstract) OR 'associating liver partition and portal vein ligation for staged hepatectomy'(Title/Abstract)) OR 'in situ split'(Title/Abstract)). A list of all references was made, and ti- tles were screened. Studies that provided information on outcomes of ALPPS in terms of complication and mortality in relation to liver function following ALPPS were selected for abstract review. Additionally, all studies examining liver function tests to guide resection in ALPPS as well as mechanistic studies to better understand the volume-function relationship were evaluated in abstract format. Modifications of ALPPS and their outcomes were reviewed. Language was restricted to English. Opinion, editorials, letters, and commentary were excluded. Single case reports and technical letters that were deemed highly relevant to our review were included, given the emerging nature of the topic. There was no restriction on study types. Several studies were excluded based on the full text review.

After selection, articles were grouped under 4 topics:

- Liver-related morbidity and mortality after ALPPS.

- Interstage liver function in ALPPS.

- Mechanisms proposed to explain the lack of congruence of volume and function.

- Impact of modifications of ALPPS on the volume/function dilemma.

\section{Results}

Literature Review Results

Figure 1 shows the review and selection process. 326 references were initially identified and 58 abstracts reviewed. A total of 29 full text articles were selected for the review.

Incidence of Liver Failure and Higher Complications after ALPPS

A total of 18 studies reported major complications and mortality after ALPPS and related those findings to postoperative liver function and PHLF (table 1). The most common criteria used in defining PHLF were the liver failure criteria of the International Study Group of Liver Surgery (ISGLS) [12], followed by the 50-50 criteria [13]. The peak bilirubin criterion [14] was used in only 2 studies. 7 of the listed studies employed more than one criterion to evaluate PHLF. 3 studies did not specify the criteria used. The incidence of PHLF after ALPPS using any combination of the three criteria ranged from 8 to $36 \%$ with the majority of larger studies demonstrating a rate of around $30 \%$. Perioperative complications were reported using the Clavien-Dindo grading system [15] in all but 2 studies. Clinically significant morbidity after ALPPS was 13$44 \%$ and $14-36 \%$ for grades $3 a$ or higher and $3 \mathrm{~b}$ or higher, respectively. 1 study demonstrated no mortality and a very low morbidity but reported a 29\% rate of ISGLS-defined liver failure. Only 1 study examined how many mortalities after ALPPS were likely due to PHLF by analyzing the causes of 28 mortalities in 320 patients. The study showed that up to $75 \%$ of all mortalities after ALPPS were likely a consequence of PHLF. It was also shown that PHLF by ISGLS criteria after stage 1 and a MELD (Model for End-stage Liver Disease) score $>10$ prior to stage 2 were significant risk factors for 90-day mortality after ALPPS, while standardized FLR volume prior to stage 2 or experience of the center performing ALPPS 


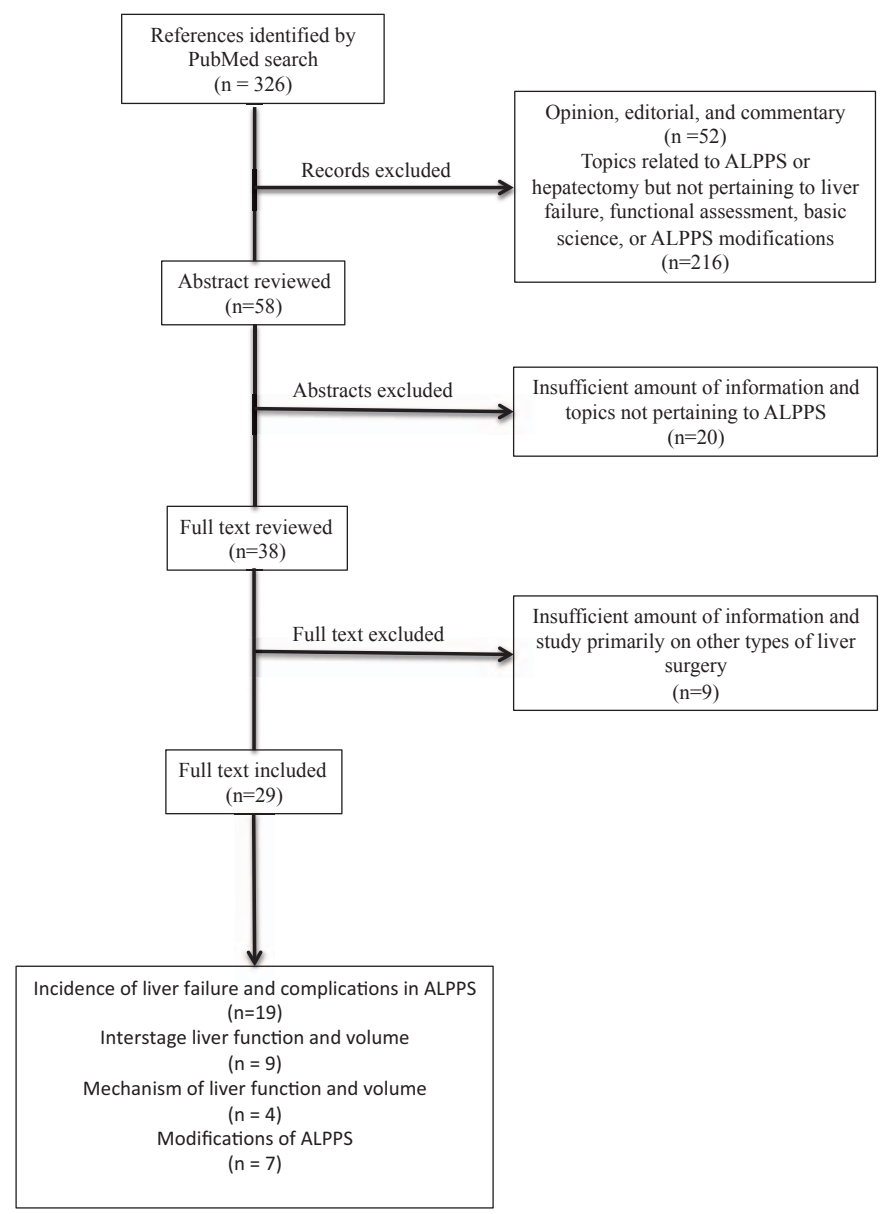

Fig. 1. Flowchart of databases searched, the strategy used, and exclusions performed.

were not [9]. A correlation between FLR volume and complications did not exist. Next to MELD score or ISGLS criteria after stage 1, kinetic growth rate of the FLR [16] and a dedicated ALPPS futility score [17] have been proposed to assess the risk of stage- 2 resection.

\section{Assessment of Interstage Liver Function}

Table 2 lists the 5 studies investigating interstage liver function assessment. So far, hepatobiliary scintigraphy (HBS) has been the test of choice due to its ability to selectively evaluate regions of the liver for function. Early reports evaluated only the proportion of HIDA (hepatobiliary iminodiacetic acid scan) signal coming from the FLR as a percentage of the total HIDA signal prior to stage 2 [18]. Since this approach yielded no information about total function of the liver, it was generally abandoned by most. Later studies used an uptake index derived from an analysis of HIDA uptake from the blood pool in the first $5 \mathrm{~min}$, as established by the Amsterdam group [19]. There are only 2 studies in ALPPS so far using this methodology [20, 21]. These studies, including 10 and 28 patients, respectively, showed that functional increase was less (28 and $29 \%$ over 6 and 7 days, respectively) than volume increase (57 and 78\% over 6 and 8 days, respectively). ICG-R15 (indocyanine green retention rate at $15 \mathrm{~min}$ ) is a global liver function test based on the pro- portion of remaining ICG after intravenous (i.v.) injection after $15 \mathrm{~min}$ and was used in 2 studies. One study showed ICG-R15 decreased from 9.9 to $7 \%$ between stages but increased to $33 \%$ after stage 2 [21]. Another study showed an increase from 3.6 to $5.4 \%$ postoperatively [16]. LiMAx (maximum liver function capacity) is another global liver function test based on hepatic enzyme metabolism, which is quantified using a breath test after i.v. methacetin has been administered. It has so far only been published in 1 single case report which demonstrated a dramatic decrease in global liver function between stage- 1 and stage-2 ALPPS [42].

\section{Investigations into the Mechanism of Function and Volume}

A total of 5 studies addressed the potential mechanism of the function/volume question after ALPPS (table 3). A first effort was directed at making sure that the volume increase measured with volumetry in ALPPS is not just edema or regenerative steatosis by using functional magnetic resonance imaging (MRI) data. It was concluded that volume increase after ALPPS is indeed cellular proliferation and not edema or steatosis according to MRI [23]. A second study came to the same conclusion [24].

Matsuo et al. [25] focused their investigation on histology specimens from patients undergoing ALPPS. Histology, electron microscopy, and immunohistochemistry staining showed findings consistent with immature hepatocytes. In a second study, immunohistochemistry and electron-microscopy of bile duct canaliculi showed weaker MDR1 staining, immature microvilli, and leaky tight junctions, despite an adequate quantity of bile duct canaliculi overall [26].

\section{Modifications of ALPPS}

A total of 7 studies on 6 different modification techniques were reviewed (table 4). Volume increase in ALPPS modification studies ranged from 53 to $76 \%$. PHLF was reported at $13.6 \%$ in only 1 study [27]. The remaining studies reported no liver failure. However, in the majority of the studies, the criteria used to define PHLF were not specified. There was no information on liver function based on HBS, ICG, or LiMAx.

\section{Discussion}

This review gives a first synopsis of data published on the volume/function problem to explain the high morbidity and mortality after the novel ALPPS procedure. It points to the available evidence that liver failure and major complications after ALPPS are higher than would be expected with the extensive increase in liver volume. It supports the claim that the high liver failure rate despite increase in volume is likely due to an intrinsic functional defect following rapid hypertrophy in classic ALPPS. This results in uncertainty as to when to progress to resection after ALPPS stage 1 has been performed. The mechanistic understanding of why rapid hypertrophy fails to provide some patients with adequate liver function despite increases in volume is still preliminary, and so far there is no data to conclude that the new ALPPS modifications proposed are helpful to overcome the volume-function problem of rapid hypertrophy. 
Tab. 1. Incidence of liver failure and complications after ALPPS

\begin{tabular}{|c|c|c|c|c|c|c|c|c|}
\hline Author [ref.] & Year & $\mathrm{n}$ & $\begin{array}{l}\text { Criteria for } \\
\text { liver failure }\end{array}$ & $\begin{array}{l}\text { PHLF after } \\
\text { stage } 1, \mathrm{n} \\
(\%)\end{array}$ & $\begin{array}{l}\text { PHLF after } \\
\text { stage } 2, \mathrm{n} \\
(\%)\end{array}$ & $\begin{array}{l}\text { Clavien grade } \\
\text { 3a or higher, n } \\
(\%)\end{array}$ & $\begin{array}{l}\text { Clavien grade } \\
3 \mathrm{~b} \text { or higher, } \mathrm{n} \\
(\%)\end{array}$ & $\begin{array}{l}\text { Liver-related } \\
\text { mortality }^{\mathrm{a}}, \mathrm{n} \\
(\%)\end{array}$ \\
\hline Linecker [17] & 2016 & 47 vs. $481^{\mathrm{b}}$ & ISGLS & $\begin{array}{l}10 \text { (23) vs. } \\
36(9)\end{array}$ & NR & NR & $\begin{array}{l}15 \text { (33) vs. } \\
30(7)\end{array}$ & $17 / 45(36)$ \\
\hline Schadde [9] & 2015 & 320 & $\begin{array}{l}\text { ISGLS } \\
50-50 \\
\text { Bili }>7^{c}\end{array}$ & $\begin{array}{c}44(14) \\
4(1) \\
5(2)\end{array}$ & $\begin{array}{l}93(30) \\
27(9) \\
21(7)\end{array}$ & NR & NR & $21 / 28(75)$ \\
\hline Schadde [28] & 2014 & 202 & $50-50$ & $16(9)$ & & $80(40)$ & $56(28)$ & $8 / 19(42)$ \\
\hline Truant [36] & 2015 & 62 & $50-50$ & $3(5)$ & $15(25)$ & $25(40)$ & NR & $3 / 8(38)$ \\
\hline Olthof [20] & 2016 & 60 & ISGLS $^{\mathrm{d}}$ & $1(2)$ & $5(8)$ & $24(40)$ & NR & $2 / 4(50)$ \\
\hline Schadde [7] & 2014 & 48 & $50-50$ & 0 & $6(13)$ & NR & $13(27)$ & NR \\
\hline Kambakamba [16] & 2016 & 36 & $\begin{array}{l}\text { ISGLS } \\
50-50\end{array}$ & $\begin{array}{l}\text { NR } \\
\text { NR }\end{array}$ & $\begin{array}{r}13(36) \\
8(22)\end{array}$ & NR & $13(36)$ & NR \\
\hline Alvarez [18] & 2015 & 30 & ISGL + 50-50 & 0 & $4(13)$ & $13(43)$ & $9(31)$ & 0 \\
\hline Wanis [37] & 2017 & 30 & $\begin{array}{l}\text { ISGLS } \\
50-50\end{array}$ & $\begin{array}{l}2(7) \\
0\end{array}$ & $\begin{array}{l}8(31) \\
1(4)\end{array}$ & NR & $8(26)$ & 0 \\
\hline Serenari [30] & 2017 & 20 & $\begin{array}{l}\text { Bili }>7 \\
\text { all } 3^{d}\end{array}$ & $\begin{array}{l}1(5) \\
0\end{array}$ & $\begin{array}{l}1(5) \\
3(15)\end{array}$ & $5(25)^{d}$ & NR & $1 / 1(100)$ \\
\hline Alvarez [38] & 2013 & 15 & ISGLS & $3(20)$ & & $5(33)$ & $4(27)$ & 0 \\
\hline Hernandez-Alejandro [39] & 2015 & 14 & ISGLS + 50-50 & $4(29)$ & & NR & $2(14)$ & 0 \\
\hline Tanaka [34] & 2015 & 11 & ISGLS & $2(18)$ & $4(36)$ & $4(36)$ & $2(18)$ & 0 \\
\hline Sala [40] & 2012 & 10 & ISGLS & $2(20)$ & & $2(20)$ & 0 & 0 \\
\hline $\operatorname{Li}[41]$ & 2013 & 9 & ISGLS & 0 & $2(22)$ & $2(22)$ & $3(33)$ & 0 \\
\hline Vivarelli [42] & 2015 & 9 & $50-50$ & 0 & $1(11.1)$ & $4(44.4)$ & NR & $1 / 1(100)$ \\
\hline Ratti [43] & 2014 & 8 & ISGLS + 50-50 & $1(13)$ & 0 & $3(38)$ & $1(13)$ & 0 \\
\hline Matsuo [25] & 2016 & 8 & ISGLS & $2(25)$ & & $1(13)$ & NR & 0 \\
\hline Matsuo [26] & 2017 & 8 & $\begin{array}{l}\text { ISGLS } \\
50-50\end{array}$ & $\begin{array}{l}3(37.5) \\
0\end{array}$ & & $3(37.5)$ & NR & 0 \\
\hline
\end{tabular}

aLiver-related mortality is the percent of 90 -day mortality.

bNumbers reported as futile vs. non-futile operations in the study.

'Peak bilirubin criterion was modified in this study to reflect bilirubin $>7 \mathrm{mg} / \mathrm{dl}$ on postoperative day 5 due to data availability.

dISGLS grade A was excluded in these studies.

PHLF = Posthepatectomy liver failure; ISGLS = International Study Group of Liver Surgery definition of liver failure according to Rahbari et al. [29]; 50-50: fifty/ fifty criterion for liver failure according to Balzan et al. [13]; Bili > 7 = bilirubin $>7 \mathrm{mg} / \mathrm{dl}$ according to Mullen et al. [14]; NR = not reported.

Very few reports on ALPPS analyzed the morbidity and mortality under the aspect of whether they are actually caused by PHLF, the very reason why regenerative maneuvers like PVE, PVL, or ALPPS are performed in extended liver resection to start with. Curiously, studies on ALPPS do not report PHLF using any of the common metrics in their analyses. The 2 studies that dissected out morbidity and mortality after ALPPS in larger cohorts beyond established severity gradings and typing of complications came to the conclusion that the vast majority of complications is due to PHLF despite adequate liver volumes prior to stage 2 [9, 28]. The first registry analysis showed that of the 19/202 patients with 90 -day mortality, 8 patients were judged to have liver failure by their clinicians and the incidence of liver failure by $50-50$ criteria in all patients was 9\% [28]. The second registry analysis focused entirely on mortality and showed that $21 / 28$ (75\%) mortalities were caused by liver failure and that $32 \%$ of all patients had liver failure using any of three criteria (ISGLS, 50-50, and peak bilirubin $>7 \mathrm{mg} / \mathrm{dl}$ ). $20 \%$ of patients with liver failure died within 90 days after ALPPS [9].
Because PHLF presents in so many different ways, it remains difficult to attribute complications incurred to liver failure without formally assessing at least some to the accepted liver failure criteria based on postoperative laboratory values of INR (international normalized ratio) and total bilirubin at postoperative day 5 and beyond [13, 14, 29]. Meticulous reports on liver failure criteria should therefore be encouraged for any future reports on ALPPS outcomes. It is interesting to note that liver failure by ISGLS criteria in published series is only $8.3 \%$ [20] or $15 \%$ [30] in the 2 series in which HBS was performed to guide clinical management, and $36 \%$ in a series [16] in which no HBS was used. It suggests that clinical management with HBS may be able to avoid liver failure after ALPPS.

Interestingly, outcomes after ALPPS in the registry studies are very similar to outcomes reported for a contemporary series of 285 extended hepatectomies in an experienced liver resection center. Only $23 \%$ of these extended hepatectomies had preoperative PVE to increase the size of the FLR [31]. There was an incidence of PHLF of $28 \%$ and a mortality rate of $9 \%$, and $84 \%$ of these mortali- 


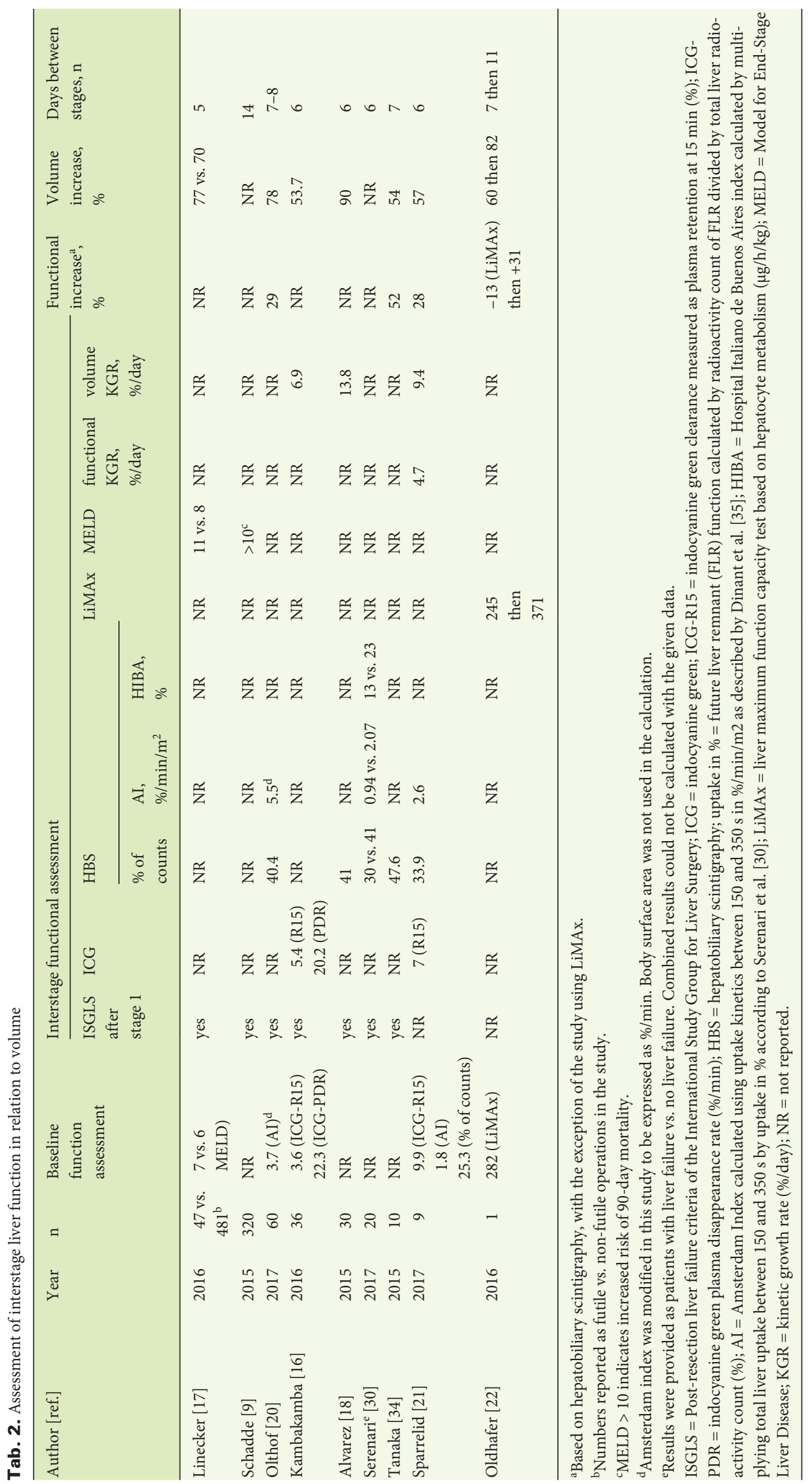


Tab. 3. Investigations into the mechanism of function and volume in ALPPS

\begin{tabular}{|c|c|c|c|c|c|}
\hline Author [ref.] & Year & $\mathrm{n}$ & Subject & Method & Findings \\
\hline Eshmuminov [23] & 2017 & 16 & $\begin{array}{l}\text { hepatocyte } \\
\text { proliferation }\end{array}$ & $\begin{array}{l}\text { human histology } \\
\text { MRI }\end{array}$ & $\begin{array}{l}\text { no increased steatosis } \\
\text { or cellular edema }\end{array}$ \\
\hline Olthof [44] & 2016 & 12 & $\begin{array}{l}\text { functional vs. } \\
\text { volume growth } \\
\text { in rabbits after } \\
\text { ALPPS }\end{array}$ & HBS & $\begin{array}{l}\text { volume but no } \\
\text { functional increase } \\
\text { when compared to } \\
\text { PVE in rabbits }\end{array}$ \\
\hline Sheng [24] & 2017 & 10 & $\begin{array}{l}\text { hepatocyte } \\
\text { proliferation }\end{array}$ & $\begin{array}{l}\text { DKI } \\
\text { IHC }\end{array}$ & $\begin{array}{l}\text { true liver hypertrophy } \\
\text { in ALPPS }\end{array}$ \\
\hline Matsuo [25] & 2016 & 8 & $\begin{array}{l}\text { hepatocyte } \\
\text { maturity }\end{array}$ & $\begin{array}{l}\text { human histology } \\
\text { IHC } \\
\text { electron microscopy }\end{array}$ & $\begin{array}{l}\text { immaturity of } \\
\text { hepatocytes }\end{array}$ \\
\hline Matsuo [26] & 2017 & 8 & $\begin{array}{l}\text { bile duct } \\
\text { canaliculi } \\
\text { network maturity }\end{array}$ & $\begin{array}{l}\text { human histology } \\
\text { IHC } \\
\text { electron microscopy }\end{array}$ & $\begin{array}{l}\text { structurally and func- } \\
\text { tionally immature bile } \\
\text { canalicular network }\end{array}$ \\
\hline
\end{tabular}

MRI = Magnetic resonance imaging; HBS = hepatobiliary scintigraphy; PVE = portal vein embolization; DKI = diffusion kurtosis imaging; IHC = immunohistochemistry. ties fulfilled ISGLS criteria for liver failure. In contrast, a recent meta-analysis on outcomes after 459 2-stage hepatectomies for colorectal liver metastases reported a mortality rate of only $3 \%$ and a major complication rate of $40 \%$ without further information on liver failure criteria [10]. The 2-stage hepatectomy approach with the regenerative liver surgery maneuvers of PVE and PVL should improve the morbidity and mortality of extended resections. Given these data, it is fair to conclude that ALPPS has the same risk of liver failure, mortality, and complications incurred by extended resection and does not seem to reduce this risk.

The most important practical question in clinical ALPPS management is how to assess function and volume prior to proceeding to stage- 2 resection. The overarching problem in the field of measuring liver function in ALPPS remains that HBS so far appears to be the only available tool to measure regional liver function in the western world [32] but there is no standardized methodology of HBS that is easily reproducible. Despite this, all 5 studies using HBS in ALPPS, including 1 case report [33], converge on the fact that while there is some increase in liver function in the FLR after ALPPS, the functional increase is always less than the volume increase between stage 1 and stage 2 (table 2). Most worrisome are the 2 studies that use HBS uptake kinetics to quantify regional liver function (also called the 'Amsterdam index'). Both studies come to the conclusion that the functional increase of the FLR after ALPPS is only $37 \%$ [20] or $49 \%$ [31] of the volume increase, respectively. Such findings indicate that volume, currently the principal determinant for progression to the second stage, overestimates the function of the FLR by up to $50 \%$, which may easily explain the high incidence of liver failure despite adequate volume. In the study of 27 patients with paired measurements, only 7 patients achieved an increase in liver function in their FLR beyond $50 \%$, and 4 of these patients took more than 7 days to get beyond 50\% function [20].

In the first reports, HBS was quantified by giving the proportion of scintigraphic signal that can be captured during the uptake phase or during the entire scan from the FLR and the portal vein- deprived side [18]. The downside of this ' $\%$ of counts' technique is that it does not indicate a drop in liver function in case the overall liver function decreases. It simply provides clinicians with a proportion of total function without quantifying total function. The study that reported a volume increase of $52 \%$ with a functional increase of $54 \%$ used this methodology and appears to indicate a congruence of volume and function increase [34].

In contrast, the Amsterdam group has long ago developed a method to derive liver function from uptake kinetics between 150 and $350 \mathrm{~s}$ after injection using the HBS scan, and established their index for liver function expressed as uptake per min per $\mathrm{m}^{2}$ [32]. Based on a series of liver resections, it has been shown that $2.7 \%$ / $\mathrm{min} / \mathrm{m}^{2}$ likely represents adequate liver function to master metabolic demands after resection [35]. An initial case report of this methodology in ALPPS [33] and a subsequent study using this methodology showed an astonishing functional deficit of the rapidly volume-increased liver [20].

The 2 studies with paired measurements prior to stage 1 and prior to stage 2 had too few outcome events to allow a solid C-statistic to determine a cut-off for preoperative liver function for the FLR [20,31]. Studies with no paired measurements before and after stage 1 are not able to provide information on the effect of rapid hypertrophy on function changes [30], but they may provide information on when to proceed with stage 2 based on functional data. The Buenos Aires group attempted to develop a cut-off, but unfortunately they invented a new HBS metrics model, the 'Hospital Italiano of Buenos Aires (HIBA)' score, which makes their results difficult to compare to other uptake kinetics data published so far and difficult to reproduce for other centers [30]. Although there appears to be an emerging consensus among many groups that ALPPS should not be performed without HBS regional liver function tests prior to stage 2, the newly developed HIBA score cut-off of $15 \%$ has to first be validated by other centers.

Of course the lack of congruence of volume and function after ALPPS has to be explained mechanistically. The first concern 
Tab. 4. Modifications of ALPPS and available data on liver failure and function

\begin{tabular}{llrllllll}
\hline Author [ref.] & Year & $\mathrm{n}$ & Modification & $\begin{array}{l}\text { Volume } \\
\text { increase, } \\
\%\end{array}$ & $\begin{array}{l}\text { PHLF, n } \\
(\%)\end{array}$ & $\begin{array}{l}\text { PHLF } \\
\text { criteria } \\
\text { used }\end{array}$ & $\begin{array}{l}\text { Clavien-Dindo } \\
\text { grade 3a or } \\
\text { higher, n (\%) }\end{array}$ & $\begin{array}{l}\text { Clavien-Dindo } \\
\text { grade 3b or } \\
\text { higher, n (\%) }\end{array}$ \\
\hline Robles [27] & 2016 & 22 & ALTPS & 61 & $3(14)$ & NR & NR & NR \\
Wang [45] & 2017 & 10 & RALPPS & 53 & 0 & NR & NR & $2(20)$ \\
Petrowsky [46] & 2015 & 6 & p-ALPPS & 60 & 0 & NR & NR & $2(33)$ \\
Gall [47] & 2014 & 5 & RALPPS & 62 & 0 & NR & 0 & 0 \\
De Santibanes [48] & 2016 & 4 & Mini ALPPS & 63 & 0 & $50-50$ & NR & NR \\
Peng [49] & 2016 & 4 & TBPVE & 66 & NR & NR & NR & NR \\
Li [50] & 2014 & 2 & Hybrid ALPPS & 76 & 0 & NR & $1(50)$ & NR \\
\hline
\end{tabular}

${ }^{a}$ Full text paper was not available in English; abstract was published in English and was used for data.

PHLF = Posthepatectomy liver failure; ALTPS = Associating Liver Tourniquet with Portal vein ligation for Staged hepatectomy: modification of ALPPS where a tourniquet is used to obliterate the flow between the portal vein-supplied and the portal vein-deprived part of the liver; RALPPS = radiofrequency-assisted ALPPS where transection is replaced by radiofrequency ablation; p-ALPPS = partial ALPPS where only partial transection is performed instead of complete transection; TBPVE $=$ terminal branches portal vein embolization, a variation of PVE pioneered in China; $\mathrm{NR}=$ not reported. raised was that the rapid and extensive volume increase in ALPPS is not true cellular proliferation of functioning hepatocytes, but interstitial edema or intracellular fat accumulation/regenerative steatosis. 2 MRI studies, 1 in patients and 1 in rats, have now debunked this concern $[23,34]$. Both studies show convincingly that ALPPS induces true cellular proliferation.

Interestingly, both hepatocytes and bile duct canaliculi, however, displayed characteristics of immaturity in histology [25, 26]. Whether these deficiencies are a transient or permanent defect of rapid hypertrophy has yet to be determined. The studies suggest that progressing to stage 2 within a week may be premature despite the impressive volumetric increase.

It may well be that the problem with liver function is an intrinsic problem only for classic ALPPS, and that the modified ALPPS approaches overcome the problem of volume/function. Unfortunately, the reports on ALPPS modifications report on very small series of patients and are generally limited to demonstrating a volume increase as large as that seen in classic ALPPS. The main focus of these reports seems to be to develop less invasive procedures based on the assumption that the complications of ALPPS stem largely from surgical severity and lack of experience of the surgeons. Functional studies of the FLR have not been added to these reports on modifications, and the awareness of the volume/function problem is limited. At this stage, reports on modifications should carefully address PHLF or, even better, evaluate liver function before and after ALPPS using metrics like HBS, LiMAx, or ICG.
The limitations of this review are primarily the small number of published studies in an emerging field as well as the small sample size in each study. It also appears that clinicians reporting on their experience with ALPPS have only limited access to liver function tests such as HBS, LiMAx, or ICG. There also remains the concern of a reporting bias across all the small uncontrolled series, especially the reports from the voluntary international ALPPS registry which has not been subject to independent monitoring or audit.

\section{Conclusion}

In summary, ALPPS has a high incidence of liver failure caused by a discrepancy between volumetric growth and functional increase of the FLR, which is alarming and needs to be better understood. Direct measurement of regional liver function may protect from liver failure after stage 2, but there is no consensus on reliable metrics. So far, there is no proof that efforts to improve ALPPS by modifications are effective to address this problem. Until these questions are addressed, ALPPS should be considered to be an experimental procedure and only be used in a highly controlled research environment.

\section{Disclosure Statement}

The authors do not have a conflict of interest for this article.

\section{References}

1 Jarnagin WR, Gonen M, Fong Y, et al: Improvement in perioperative outcome after hepatic resection: analysis of 1,803 consecutive cases over the past decade. Ann Surg 2002;236:397-406, discussion 406-397.
2 Van Lienden KP, van den Esschert JW, de Graaf W, et al: Portal vein embolization before liver resection: a systematic review. Cardiovasc Intervent Radiol 2013; $36: 25-34$.
3 Nadalin S, Testa G, Malago M, et al: Volumetric and functional recovery of the liver after right hepatectomy for living donation. Liver Transpl 2004;10:1024-1029. 
4 Abulkhir A, Limongelli P, Healey AJ, et al: Preoperative portal vein embolization for major liver resection: a meta-analysis. Ann Surg 2008;247:49-57.

5 Farges O, Belghiti J, Kianmanesh R, et al: Portal vein embolization before right hepatectomy: prospective clinical trial. Ann Surg 2003;237:208-217.

6 Schnitzbauer AA, Lang SA, Goessmann H, et al: Right portal vein ligation combined with in situ splitting induces rapid left lateral liver lobe hypertrophy enabling 2-staged extended right hepatic resection in small-forsize settings. Ann Surg 2012;255:405-414.

7 Schadde E, Ardiles V, Slankamenac K, et al: ALPPS of fers a better chance of complete resection in patients with primarily unresectable liver tumors compared with conventional-staged hepatectomies: results of a multicenter analysis. World J Surg 2014;38:1510-1519.

8 De Santibanes E, Clavien PA: Playing Play-Doh to prevent postoperative liver failure: the 'ALPPS' approach. Ann Surg 2012;255:415-417.

9 Schadde E, Raptis DA, Schnitzbauer AA, et al: Prediction of mortality after ALPPS stage-1: an analysis of 320 patients from the International ALPPS Registry. Ann Surg 2015;262:780-785, discussion 785-786.

10 Lam VW, Laurence JM, Johnston E, et al: A systematic review of two-stage hepatectomy in patients with initially unresectable colorectal liver metastases. HPB (Oxford) 2013;15:483-491.

11 Lang H, de Santibanes E, Clavien PA: Outcome of ALPPS for perihilar cholangiocarcinoma: case-control analysis including the first series from the international ALPPS registry. HPB (Oxford) 2017;19:379-380.

12 Rahbari NN, Reissfelder C, Koch M, et al: The predictive value of postoperative clinical risk scores for outcome after hepatic resection: a validation analysis in 807 patients. Ann Surg Oncol 2011;18:3640-3649.

13 Balzan S, Belghiti J, Farges O, et al: The '50-50 criteria' on postoperative day 5: an accurate predictor of liver failure and death after hepatectomy. Ann Surg 2005; 242:824-828, discussion 828-829.

14 Mullen JT, Ribero D, Reddy SK, et al: Hepatic insufficiency and mortality in 1,059 noncirrhotic patients undergoing major hepatectomy. J Am Coll Surg 2007; 204:854-862, discussion 862-854.

15 Dindo D, Demartines N, Clavien PA: Classification of surgical complications. Ann Surg 2004;240:205-213.

16 Kambakamba P, Stocker D, Reiner CS, et al: Liver kinetic growth rate predicts postoperative liver failure after ALPPS. HPB (Oxford) 2016;18:800-805.

17 Linecker M, Stavrou GA, Oldhafer KJ, et al: The ALPPS risk score: avoiding futile use of ALPPS. Ann Surg 2016;264:763-771.

18 Alvarez FA, Ardiles V, de Santibanes M, et al: Associating liver partition and portal vein ligation for staged hepatectomy offers high oncological feasibility with adequate patient safety: a prospective study at a single center. Ann Surg 2015;261:723-732.

19 De Graaf W, Vetelainen RL, de Bruin K, et al: 99m Tc-GSA scintigraphy with SPECT for assessment of hepatic function and functional volume during liver regeneration in a rat model of partial hepatectomy. J Nucl Med 2008;49:122-128.

20 Olthof PB, Tomassini F, Huespe P, et al: Hepatobiliary scintigraphy to evaluate liver function in ALPPS: liver volume overestimates liver function. Surgery 2017;162 775-783.
21 Sparrelid E, Jonas E, Tzortzakakis A, et al: Dynamic evaluation of liver volume and function in associating liver partition and portal vein ligation for staged hepatectomy. J Gastrointest Surg 2017;21:967-974.

22 Oldhafer F, Ringe KI, Timrott K, et al: Monitoring of liver function in a 73-year old patient undergoing 'Associating Liver Partition and Portal vein ligation for Staged hepatectomy': case report applying the novel liver maximum function capacity test. Patient Saf Surg 2016;10:16.

23 Eshmuminov D, Tschuor C, Raptis DA, Boss A, et al: Rapid liver volume increase induced by associating liver partition with portal vein ligation for staged hepatectomy (ALPPS): is it edema, steatosis, or true proliferation? Surgery 2017;161:1549-1552.

24 Sheng RF, Wang HQ, Jin KP, et al: Histogram analyses of diffusion kurtosis indices and apparent diffusion coefficient in assessing liver regeneration after ALPPS and a comparative study with portal vein ligation. J Magn Reson Imaging 2017;DOI: 10.1002/jmri.25793.

25 Matsuo K, Murakami T, Kawaguchi D, et al: Histologic features after surgery associating liver partition and portal vein ligation for staged hepatectomy versus those after hepatectomy with portal vein embolization. Surgery 2016;159:1289-1298.

26 Matsuo K, Hiroshima Y, Yamazaki K, et al.: Immaturity of bile canalicular-ductule networks in the future liver remnant while associating liver partition and portal vein occlusion for staged hepatectomy (ALPPS). Ann Surg Oncol 2017;24:2456-2464.

27 Robles R, Parrilla P, Lopez-Conesa A, et al: Tourniquet modification of the associating liver partition and portal ligation for staged hepatectomy procedure. $\mathrm{Br} \mathrm{J}$ Surg 2014;101:1129-1134, discussion 1134.

28 Schadde E, Ardiles V, Robles-Campos R, et al: Early survival and safety of ALPPS: first report of the International ALPPS Registry. Ann Surg 2014;260:829-836, discussion 836-828.

29 Rahbari NN, Garden OJ, Padbury R, et al: Posthepatectomy liver failure: a definition and grading by the International Study Group of Liver Surgery (ISGLS). Surgery 2011;149:713-724.

30 Serenari M, Collaud C, Alvarez FA, et al: Interstage assessment of remnant liver function in ALPPS using hepatobiliary scintigraphy: prediction of posthepatectomy liver failure and introduction of the HIBA index. Ann Surg 2017;DOI: 10.1097/SLA.0000000000002150.

31 Truant S, El Amrani M, Skrzypczyk C, et al: Factors associated with fatal liver failure after extended hepatectomy. HPB (Oxford) 2017;19:682-687.

32 Olthof PB, van Gulik TM, Bennink RJ: Optimal use of hepatobiliary scintigraphy before liver resection. HPB (Oxford) 2016;18:870

33 Cieslak KP, Olthof PB, van Lienden KP, et al: Assessment of liver function using ${ }^{99 \mathrm{~m}} \mathrm{Tc}$-mebrofenin hepatobiliary scintigraphy in ALPPS (associating liver partition and portal vein ligation for staged hepatectomy). Case Rep Gastroenterol 2015;9:353-360.

34 Tanaka K, Matsuo K, Murakami T, et al: Associating liver partition and portal vein ligation for staged hepatectomy (ALPPS): short-term outcome, functional changes in the future liver remnant, and tumor growth activity. Eur J Surg Oncol 2015;41:506-512.
35 Dinant S, de Graaf W, Verwer BJ, et al: Risk assessment of posthepatectomy liver failure using hepatobiliary scintigraphy and CT volumetry. J Nucl Med 2007; 48:685-692.

36 Truant S, Scatton O, Dokmak S, et al: Associating liver partition and portal vein ligation for staged hepatectomy (ALPPS): impact of the inter-stages course on morbi-mortality and implications for management. Eur J Surg Oncol 2015;41:674-682.

37 Wanis KN, Buac S, Linecker M, et al: Patient survival after simultaneous ALPPS and colorectal resection. World J Surg 2017;41:1119-1125.

38 Alvarez FA, Ardiles V, Sanchez Claria R, et al: Associating liver partition and portal vein ligation for staged hepatectomy (ALPPS): tips and tricks. J Gastrointest Surg 2013;17:814-821.

39 Hernandez-Alejandro R, Bertens KA, Pineda-Solis K, Croome KP: Can we improve the morbidity and mortality associated with the associating liver partition with portal vein ligation for staged hepatectomy (ALPPS) procedure in the management of colorectal liver metastases? Surgery 2015;157:194-201.

40 Sala S, Ardiles V, Ulla M, et al: Our initial experience with ALPPS technique: encouraging results. Updates Surg 2012;64:167-172.

$41 \mathrm{Li} \mathrm{J,} \mathrm{Girotti} \mathrm{P,} \mathrm{Königsrainer} \mathrm{I,} \mathrm{et} \mathrm{al:} \mathrm{ALPPS} \mathrm{in} \mathrm{right} \mathrm{tri-}$ sectionectomy: a safe procedure to avoid postoperative liver failure? J Gastrointest Surg 2013;17:956-961.

42 Vivarelli M, Vincenzi P, Montalti R, et al: ALPPS procedure for extended liver resections: a single centre experience and a systematic review. PloS One 2015; 10:e0144019.

43 Ratti F, Cipriani F, Gagliano A, et al: Defining indications to ALPPS procedure: technical aspects and open issues. Updates Surg 2014;66:41-49.

44 Olthof PB, Schadde E, van Lienden KP, et al: Hepatic parenchymal transection increases liver volume but not function after portal vein embolization in rabbits. Surgery 2017;162:732-741.

45 Wang Q, Yan J, Feng X, et al: Safety and efficacy of radiofrequency-assisted ALPPS (RALPPS) in patients with cirrhosis-related hepatocellular carcinoma. Int J Hyperthermia 2017;33:846-852.

46 Petrowsky H, Gyori G, de Oliveira M, et al: Is partialALPPS safer than ALPPS? A single-center experience. Ann Surg 2015;261:e90-92.

47 Gall TM, Sodergren MH, Frampton AE, et al: Radiofrequency-assisted Liver Partition with Portal vein ligation (RALPP) for liver regeneration. Ann Surg 2015; 261:e45-46.

48 De Santibanes E, Alvarez FA, Ardiles V, et al: Inverting the ALPPS paradigm by minimizing first stage impact: the Mini-ALPPS technique. Langenbecks Arch Surg 2016;401:557-563.

49 Peng SY, Huang CY, Li JT, et al: Terminal branches portal vein embolization for planed hepatectomy (Article in Chinese). Zhonghua Wai Ke Za Zhi 2016;54: 664-668.

50 Li J, Kantas A, Ittrich H, et al: Avoid 'all-touch' by hybrid ALPPS to achieve oncological efficacy. Ann Surg 2016;263:e6-7. 